\title{
La población de Dúrcal del Valle de Lecrín en el libro de habices del año 1502
}

\section{The village of Dúrcal in the Valley of Lecrin from the Habices book of year 1502}

\author{
Manuel ESPINAR MORENO \\ Departamento de Historia Medieval y CCTTHH \\ Universidad de Granada \\ mespinar@ugr.es
}

Recibido: marzo 2010

Aceptado: diciembre 2010

\section{RESUMEN}

En este trabajo estudiamos los bienes habices de Dúrcal, lugar del Valle de Lecrín (Granada). Gracias a las noticias aportadas por los apeadores y conocedores de estos bienes podemos conocer cómo eran los centros religiosos de cada uno de los barrios de esta población. Se citan las mezquitas y rábitas musulmanas que fueron convertidas en iglesias y ermitas por los cristianos. Tenemos noticias sobre bienes urbanos y rústicos donados por los creyentes musulmanes para hacer frente a los gastos de los alfaquíes y edificios dedicados al culto. Además se nos ofrecen noticias sobre la economía y sociedad musulmana y más tarde cristiana de esta comarca del reino de Granada.

Palabras clave: Habices. Mezquitas y rábitas. Estructuras urbanas. Sociedad. Economía. Arqueología y Cultura material.

\begin{abstract}
This study about habices goods of the Dúrcal, a place located at the Lecrin Valley (Granada). The news contributed by the surveyors and connoisseurs of these goods through we can know how they were the religious centers of each one of the districts of this population. The Moslem mosques and rábitas that were turned churches and hermitages by the Christians are quoted. We have news on urban and rustic goods donated by the Muslim believers to face the expenses of the alfaquíes and buildings dedicated to the cult. Also, the news offer an important data set about economy and Muslim society of this place at kingdom of Granada.
\end{abstract}

Key words: Habices. Mosques and rábitas. Urban structures. Society. Economy. Archaeology and material Culture.

SUMARIO. 1. Introducción. 2. Habices del barrio de Margena. 3. Bienes del alfaquí de la mezquita de Margena. 4. Habices de la rábita de Margena. 5. Habices de la rábita del barrio de Azuac o Azuar. 6. Bienes de la iglesia o rábita. 7. Habices de los caminos de Hauc Azuac. 8. Habices de Çubia. 9. Habices del barrio de Almauçeta. 10. Habices de la rábita de Almauçeta. 11. Habices de la rábita Almauçeta Alolia. 12. Habices del alfaquí de la rábita del barrio de Abdarrof. 13. Habices de la rábita de Abdarrof. 14. Habices de los pobres. 15. Habices del barrio de Belina o Belinar. 16. Habices de la rábita Belina. 17. Habices de los cautivos. 18. Habices de la rábita de Belinar la Baja. 19. Conclusión. 


\section{INTRODUCCIÓN}

Los bienes habices cumplieron un papel importante en la sociedad musulmana medieval, son legados piadosos destinados a un fin social de la comunidad en sus más variados aspectos. Estos se destinan a la asistencia de necesitados como mezquinos, pobres, enfermos y huérfanos, enseñanza, reparación de obras públicas, caminos, puentes, acueductos, fuentes, pozos, acequias, edificios, obras piadosas como redención de esclavos, auxilio a los enfermos, fundación y mantenimiento de mezquitas, rábitas, gimas, medersas, escuelas, madrazas y otras necesidades que estén encaminadas a solucionar problemas y proporcionar el bien público exigido por las leyes coránicas y de la tradición, siempre que no se aparten de lo enseñado por el Profeta. Las tierras, aguas, árboles, casas, hornos, tiendas y otros edificios, poco a poco, se convierten en habices como medio de eludir las presiones del fisco o para realizar una acción querida por Allah y recomendada por el Profeta. Para la etapa nazarí contamos con algunos documentos que aluden a los habices ${ }^{1}$. Son primordiales para el conocimiento de la vida de las poblaciones medievales como Dúrcal de la que no conocemos hasta el momento prácticamente nada sobre su pasado medieval si exceptuamos algunas noticias sobre estructuras defensivas y algún hallazgo arqueológico.

Entre las poblaciones ubicadas en la comarca del Valle de Lecrín se mencionan varias alquerías como las Albuñuelas, Lanjarón, Padúl, Talará y Mondújar entre otras. El geógrafo Idrīsī dice en el siglo XII que Mondújar era un manzil o parador donde los viajeros podían adquirir pescado y alimentos en sus viajes ${ }^{2}$. En época

${ }^{1}$ C. SÁNCHEZ ALBORNOZ: La España musulmana según los autores islamitas y cristianos medievales. Espasa-Calpe, Madrid, 3/1973, pp. 510-512. E. LAFUENTE ALCÁNTARA: Historia de España. Tom. III, pág. 165. L. SECO DE LUCENA PAREDES: "La administración central de los nazaríes", Cuadernos de la Alhambra, 10-11, (1974-1975), pág. 26. L. SECO DE LUCENA: Documentos arábigo-granadinos. Madrid, 1961, págs. 12-15, texto árabe y traducción. J. RIBERA Y TARRAGO y M. ASÍN PALACIOS: Manuscritos árabes y aljamiados de la biblioteca de la Junta. Madrid, 1912, págs. 238 y 261-262. También se alude a los habices de las murallas de Granada en el reparto del río Beiro en época del sultán Muhammad IX. Sobre los bienes habices en general puede confrontarse Carmina VILLANUEVA RICO y Andrés SORIA ORTEGA: "Fuentes toponímicas granadinas. Los libros de bienes habices", Al-Andalus, XIX, (1954), pp. 457-462; Juan MARTÍNEZ RUIZ: "Un capítulo de toponimia árabe granadina en el siglo XV", Tamuda, II (1954), pp. 326-339; Carmina VILLANUEVA RICO: Casas, mezquitas y tiendas de los habices de las iglesias de Granada. Edición, introducción e índices. Madrid: Instituto Hispano-Árabe de Cultura, 1966; Habices de las mezquitas de la ciudad de Granada y sus alquerías. Madrid: Inst. Hispano-Árabe de Cultura, 1961 y "Un curioso pleito sobre los habices del Marquesado del Cenete", Miscelánea de Estudios dedicados al Profesor A. Marín Ocete. Granada, 1974, Tom. II, pp. 1153-1166.

${ }^{2}$ E. LEVI-PROVENÇAL: "España musulmana", Historia de España dirigida por R. Menéndez Pidal, Tomo V, Madrid, 1973, pág. 189, nota 226. Sobre el Valle de Lecrín y los habices puede verse J. ALBARRACÍN NAVARRO: "Un documento granadino sobre los bienes de la mujer de Boabdil en Mondujar", Actas del I Congreso de Historia de Andalucía, Andalucía Medieval, Córdoba, 1978, vol. II, pp. 339-348; C. ESPEJO: "Rentas de los habices y de la Hagüela", Revista Castellana, 25-26, (1918-1919); K. GARRAD: "La renta de los habices "de los mezquinos" de las Alpujarras y Valle de Lecrín. Algunos datos sobre su administración a mediados del siglo XVI", Miscelánea de Estudios 
nazarí estos lugares estaban incluidos en la taha de Alaclín, en el camino a la Alpujarra, en la falda sur de la sierra de Almijara, una de las estribaciones de Sierra Nevada. Apenas contamos hoy con testimonios escritos de época musulmana. La primera relación que conocemos sobre las alquerías de esta comarca o distrito la tenemos en una relación de bienes habices de 1502. Posteriormente contamos con el texto latino de la Bula de Erección del Arzobispado de Granada de 1505 en el que se nos ofrecen los lugares y las iglesias que se implantaron en esta zona sobre las mezquitas anteriores. El texto latino dice lo siguiente:

"Erige las Yglesias del Valle. Et in taha de Valdelecrin in ecclesia parochiali Sancta Mariae loci de Arrastanal cum suis annexis de Melexis, Amulchas, Alauxa, Barmelaz, Naio, Saleris et Cautil, locorum Granatensis dioecesis, quatuor benefitia simplitia seruitoria et quatuor sacristias. In ecclesia parochiali Sanctae Mariae loci de Veznar cum suis annexis de Tablate, Pinos de Rey, Yzbur, Atalarat, Mondujar, Acequia et Achite, locorum Granatensis dioecesis, tria simplitia seruitoria benefitia et tres sacristias. In ecclesia parochiali Sanctae Mariae loci de Padul cum suis annexis de Concha, Coxbixar, Durcal et Nigueles, locorurn Granatensis dioecesis, tria benefitia simplitia seruitoria et tres sacristias. In ecclesia parochiali Sanctae Mariae loci de Najaronsepe dictae Granatensis dioecesis, duo benefitia simplitia seruitoria et duas sacristias, auctoritate apostolica praedicta qua fungimur in hac parte de regis et reginae, dominorum nostrorurn patronorum instantia et petitione tenore praesentium (ut praefertur) creamus et instituimus"3.

Restábal y sus anejos tiene cuatro beneficiados y cuatro sacristanes, la Iglesia de Beznar y sus anejos tres beneficiados y tres sacristanes, el Padúl y sus anejos otros tres beneficiados y tres sacristanes y Lanjarón dos beneficiados y dos sacristanes.En total se nos citan veintidós iglesias levantadas sobre antiguas mezquitas aunque los centros religiosos musulmanes eran más numerosos, las rábitas se convirtieron en

Árabes y Hebraicos, II, (1953), pp. 41-48: M. ESPINAR MORENO y J. ABELLÁN PÉREZ: "Las rábitas en Andalucía. Fuentes y metodología para su estudio", La Rapita Islamica: História Institucional i altres Estudis Regionals. I Congrès de Les Rápites de l'Estat Espanyol (7-10 setembre 1989) en História Institucional i altres Estudis Regionals. San Carles de la Rápita, 1993, pp. 131-176; M. ESPINAR MORENO: "Las rábitas de las tierras granadinas en las fuentes documentales. Arqueología y toponimia". La rábita en el Islam. Estudios Interdisciplinares. Ajuntament de San Carles de la Rápita-Universidad d'Alacant, 2003, pp. 1-20; "La alquería de Mondújar: mezquita y rábitas, cementerios, barrios y otras estructuras urbanas y rurales", Anaquel de Estudios Arabes, 2001, pp. 277-294 y "Habices de los centros religiosos y del rey en Mondujar (Valle de Lecrín, Granada) en época musulmana", Homenaje a la Profesora Carmen Batlle $i$ Gallart, Acta Historica et Archaeologica Mediaevalia, 26, Barcelona, 2004, pp. 1174-1189; M. ESPINAR MORENO y C. GONZÁLEZ MARTÍN: Libro de Apeo y Repartimiento de Mondújar (Valle de Lecrín). Granada, 2008. M. ESPINAR MORENO, "Habices de los centros religiosos musulmanes de la alquería de Acequias en 1502", Anaquel de Estudios Árabes, 20, 2009, pp. 57-81; Idem, "Habices de la Mezquita Aljama de Madina Garnata o Iglesia Mayor de Granada en el Valle de Lecrín", Studia Orientalia, 107, Societas Orientalis Fennica, Helsinki, 2009, pp. 51-80.

${ }^{3}$ La Erección de la Santa Iglesia Metropolitana de Granada y de las demás de su Arzobispado. Manuscrito de la Universidad de Granada de 1592. 
ermitas y no aparecen en el documento de la Erección de las iglesias. Por tanto el territorio de Dúrcal lo encontramos dependiendo de la iglesia principal de Padúl, con sus anejos de Cónchar, Coxbíxar y Nigüelas, servidas por tres beneficios simples servideros y tres sacristías. En el repartimiento realizado en 1531 para el cobro de la farda en el Valle de Lecrín se sitúan las poblaciones de Padúl, Dúrcal, Cóncha, Cosbíxar, Nigueles, Acequia, Mondújar, Hatalarafe o Hatalarab, Chit o Chite, Béznar, Tablate, Lanjarón, Yxbar, Pinos del Rey, Restábal, Melegís, Aleuxa, Mulchas, Saleres, Najo y Cautihueles que entregaban en total 92.672 maravedíes a la corona castellana ${ }^{4}$. Con pequeñas variantes los recoge Mármol Carvajal elevándolos a veinte, pues en ocasiones hace dos de uno, como ocurre con Harat y Alarabat y las Albuñuelas's. Sobre los habices de esta comarca se han realizado varios trabajos ${ }^{6}$ que complementan a otros llevados a cabo en otras tierras del reino de Granada? ${ }^{7}$ En cuanto a Dúrcal hasta el momento no teníamos ninguna noticia sobre estos bienes ni conocíamos nada sobre cómo era la población en la época musulmana y mudéjar. Las noticias nos permiten ver la alquería y sus distintos barrios, Pagos, tierras y otros detalles que analizamos a continuación.

${ }^{4}$ Datos sacados del Archivo de la Alhambra.

${ }^{5}$ L. del MÁRMOL CARVAJAL: Historia del rebelión y castigo de los moriscos del Reino de Granada, B.A.E, Tomo I, Madrid, 1946, Libro 4, Cap. XXXI, págs. 212-213. F. VILLEGAS MOLINA: El Valle de Lecrín. Estudio geográfico. Instituto de Geografía Aplicada del Patronato "Alonso de Herrera", Granada, 1972.

${ }^{6}$ Además de la bibliografía que citamos en las notas puede Cf. M. ESPINAR MORENO: "Donación de aguas de Mohamad Abencaxon a los habices de la mezquita de Acequias (Valle de Lecrín) en 1440. Pleitos entre los vecinos en época cristiana", Miscelánea de Estudios Árabes y Hebráicos. Sección Islam, 56, 2007, pp. 59-80; Idem: "Habices de Mondújar en 1502". Castilla y el mundo feudal. Homenaje al Profesor Julio Valdeón Baruque, Universidad de Valladolid, 2009, vol. II, pp. 157-166; Idem, "Las Albuñuelas en el Libro de Habices del año 1502. The Albuñuelas from the Habices book of year 1502", Miscelánea de Estudios Árabes y Hebráicos, 57, 2008, pp. 51-74; Idem, "Estructura urbana de Lanjarón a través del Libro de Habices de 1502. The Lanjaron urban structure from the Habices book of year 1502", Revista del Centro de Estudios Históricos de Granada y su Reino, 20, Granada, 2008, pp. 175-193.

${ }^{6}$ E. LEVI-PROVENÇAL: "España musulmana", Historia de España dirigida por R. Menéndez Pidal, Tomo V, Madrid, 1973, pág. 189, nota 226.

${ }^{7}$ M. ESPINAR MORENO. "Gabia la Grande: Toponimia y Onomástica según los Libros de Habices". Estudios Románicos dedicados al Prof. Andrés Soria Ortega, Tomo I, Granada, 1985, pp. 71-88; "Bienes habices de Churriana de la Vega (1505-1548)", Cuadernos de Estudios Medievales, VI-VII, Granada, 1989, pp. 55-78; "Apeo y deslinde de los habices de Dílar (1547)", Miscelánea de Estudios Arabes y Hebraicos, XXIX-XXX , Granada, 1980-1981, pp. 135-161; M. ESPINAR MORENO y J. MARTÍNEZ RUIZ: "La alquería de Monachil a mediados del siglo XVI", Cuadernos de la Biblioteca Española de Tetuán, 23-24, Granada, 1981, pp. 191-278. M. ESPINAR MORENO: "Noticias para el estudio de la alquería de Gójar. Bienes Habices", Cuadernos de Estudios Medievales, X-XI, Granada, 1983, pp. 105-148; "La alquería de Otura. Datos para el estudio del Reino de Granada", Anales de la Universidad de Cádiz, I, Cádiz, 1985, pp. 63-78; "Notas sobre la alquería de Cájar (1505-1547)", Cuadernos de Estudios Medievales, XIV-XV, Granada, 1985-1987, pp. 47-60. Además puede Cf. P. HERNÁNDEZ BENITO: La Vega de Granada a fines de la Edad Media según las rentas de los habices. Granada, 1990. 
La relación de bienes habices que conocemos para Dúrcal nos la proporciona un vecino de la alquería llamado Juan Moxarri. Este conoce perfectamente cada uno de los bienes, en sus declaraciones va detallando el centro religioso al que pertenecen, los bienes asignados a los alfaquíes que sirven las mezquitas y rábitas de los barrios de esta población, los demás bienes que declara estaban destinados a fines concretos como dejaron de manifiesto los creyentes que los donaron. Entre las noticias que podemos destacar nos encontramos algunos barrios como el denominado de Margena, Margina, Mergina, Malchena con su mezquita principal o rábita, convertida en iglesia por los cristianos. En este lugar destacan el Pago de Margena, el barranco de Margena, el onsario de Margena donde se entierran los creyentes, el camino del Pago de Margena, la Carreyra del Amaz, la acequia de Margena y otros elementos rurales como la Gena, la falda del monte, el pozo con sus correspondientes habices, la torre de la iglesia o alminar con los suyos, propiedades de la escuela, bienes de sepulturas, bienes habices de la acequia, la calle, el horno, etc.

En el barrio de Zuac, Azuac o Azuar llamado Hauc Azuac encontramos la rábita Azuac o Azuar convertida en ermita, el Pago de Azuac, el barranco, el macaber o almacaber denominado en otros pasajes del texto onsario del Pago de Zucar, la alberca del Pago de Zuac, la torre de la iglesia o alminar, acequia, camino, el horno de Hauc Azuac, etc.

En el barrio de Almauçeta, Mauçeta o el Mauçeta, tenemos las rábitas conocidas como Almauçeta Alolia o la Alta y Almauçeta la Baxa, las casas de estos centros religiosos, el horno compartido entre ambas rábitas, osario o macaber del Pago del Mauçeta, etc.

En el barrio de Abdarrof encontramos la rábita convertida en ermita, el osario del Pago de Abdarrof, el horno, una haza de los habices que está al lado del castillo, la vivienda de la rábita, etc.

En el barrio de Belinar o Belena encontramos otras dos rábitas llamada la Alta y la Baja, en el texto se citan como rábita de Beninar, Belena, rábita Belena, rábita Belila, convertidas en ermitas, el macaber u osario del Pago de Belina, casa de la rábita Belina junto a una acequia llamada acequia de Belinar, etc.

Las acequias más importantes se encuentran en el Pago de Margena, Pago de Abdarof, Abdarrof o Abdorrof, Pago del Valat, Pago de Beninar, Pago de Zucac, Pago de Levy, Pago del Mauçeta, etc. Los caminos más importantes son los del Pago de Margena, Pago del Mauçeta, Pago de Zucac, Pago de Azuac, etc. Las eras junto al Pago de Belina, las eras del Pago de Zucar, algunas hazas tienen su propio nombre como ocurre con Fadin Almohzen, Fadin Alfor, Fadin Alcoronbe, Fadin Almuhdara, el Mofaja, Fadin Alcabar, huerta de Hamza, etc. Entre los personajes más importantes en 1502 conocemos al alfaquí Hamet, alguasyl Gia, alfaqui Beni, alguacil Obeyde, alguacil Hernando de Çafra, alfaquí Ben Atyb o Atic, alfaquí Benaçam, alfaquí Alí, alguacil Apoayaf, y otros personajes cristianos como García de Rojas, el conde de Tendilla, etc.

Es una relación de bienes muy interesante si tenemos en cuenta que una población como Dúrcal estaba compuesta por cinco barrios con sus correspondientes mezquitas y rábitas, conocemos varios alfaquíes y alguaciles, y 
otras estructuras urbanas y rústicas que hay que completar con nuevas relaciones de bienes como la de 1547, fecha en que se apearon de nuevo los habices. Son noticias de primera mano que nos permiten saber cómo se estructura esta población sobre la que hasta el momento no conocíamos sino sólo el nombre.

\section{HABICES DEL BARRIO DE MARGENA}

En el Barrio de Margena o Margina encontramos gran cantidad de bienes habices que están distribuidos en 1502 entre el alfaquí que sirve la mezquita de este lugar, bienes destinados a la conservación del edificio religioso y gastos de culto, bienes asignados a los mezquinos y pobres, los de los cautivos y los que permiten la conservación de la acequia que trae el agua hasta el centro religioso, casas de los vecinos y riego de las fincas. El estudio de ellos nos va a permitir profundizar en el conocimiento de uno de los barrios que formaron la alquería de Dúrcal en la época musulmana, datos muy importantes para el conocimiento de las estructuras urbanas nazaríes de las que todavía estamos faltos de noticias en muchas comarcas del reino como ocurre en el Valle de Lecrín a pesar de los estudios que se están desarrollando sobre esta comarca.

\section{BIENES DEL ALFAQUÍ DE LA MEZQUITA DE MARGENA}

El alfaquí de esta mezquita controla algunos bienes urbanos y rústicos con los que vive él y su familia, estos son:

\begin{tabular}{|c|c|c|c|}
\hline Bienes & Pago & Superficie & Linderos \\
\hline $\begin{array}{l}\text { Casa } \\
\text { Horno }\end{array}$ & - & - & calle y Abenchuy \\
\hline Hazas & Pago de Margena & 21 marjales & Varios \\
\hline Secanos & Pago de Margena & 1'5 marjales & Varios \\
\hline Secano & Pago del Mauçeta & ------------ & Varios \\
\hline Viñas & Pago de Margena & $2^{\prime} 5$ marjales & Varios \\
\hline
\end{tabular}

Entre los bienes habices que controla el alfaquí de la mezquita de Margena encontramos una casa y un horno. La vivienda nos dice el apeador de los bienes que tiene como linderos la calle y la casa de Abenchuy. El horno corresponde al barrio de Mergina o Margena. No sabemos nada sobre las dimensiones de estos bienes urbanos. La mayor parte de los bienes son tierras de regadío, secano y viñedo, es decir bienes rústicos. La primera de las fincas alcanza una superficie de dos marjales $^{8}$, alinda con el camino y las tierras de Alpuxarri. Continúa otra de un

${ }^{8}$ El marjal equivale a 5 áreas y 25 centiáreas, se utilizó en la etapa nazarí en tierras de regadío (marŷa) frente al cadae o cadah para las de secano, aproximadamente equivale a 527 metros cuadrados. Cf. L. MORELL Y TERRY: Equivalencias métricas de la provincia de Granada. Granada, 1909. M. ESPINAR MORENO: "Medidas de peso, capacidad y otras en las Alpujarras según los Libros de Habices", Cuadernos de Geografí, 11, Granada, 1983, pp. 309-318. Esta medida del árabe 
marjal que tiene como linderos la de Adaudaz y las de Alguaxari. Otra de otro marjal está delimitada por la de Alpuxarri y Abdilfar. Más grande es otra de tres marjales que está junto a un barranco y el osario u "honsario" de este Pago de Margena, es decir un macaber o cementerio musulmán donde se entierran los creyentes. Otra de la misma superficie alinda con una tierra de Adaudaz y un camino. Sigue otra de la misma extensión situada al lado de otra de Abdilhac y el camino. Otro marjal está delimitada por la de Abdilhac y la de Abdulaziz. Se describe otra junto a las de Alpuxarri y la de el Harrar. Se describe otra, de un marjal y medio, junto a las de Alharrac y la de Alboruc. Junto a este tenemos otro pedazo de tierra que alinda con las de Alpuxarri y el Boruc. Se detalla otra, de tres marjales, con dos aceitunos, que está delimitada por todas sus partes con fincas de Alpuxarri. La última de las tierras de regadío alcanza medio marjal de extensión y alinda con las de Aben Eluyn y la de Abdilhac.

En cuanto a las tierras de secano en el Pago de Margena se detalla una haza de un marjal alindando con la Carreyra del Amaz y las posesiones del Boruc. Otro secano del mismo Pago tiene medio marjal de cultivo que alinda con las tierras de Almuale Alí y el camino. Se detallan otros dos pedazos de tierra de secano con unos arbolejos o árboles pequeños alindando con las fincas de Ataudaz y las del Borçayle, no sabemos la superficie que tienen para el cultivo. La última de las fincas de secano se ubica en el Pago del Mauçeta que alinda con las propiedades de Atobarri y las del Montari, tampoco sabemos la extensión que alcanza.Las tierra de viñedo del Pago de Margena son dos fincas. La primera tiene medio marjal y alinda con las de Alharrac y una acequia. La segunda, de dos marjales, alinda con las de Aben Eluyn y el camino.

Además encontramos varios árboles controlados por este alfaquí que pasamos a analizar en el cuadro siguiente. Todos ellos son aceitunos u olivos lo que nos indica la importancia del aceite en la economía familiar de esta comarca.

Los dos primeros aceitunos se encuentran plantados en dos pedazos de tierra del Pago de Margena que pertenece a los habices. Los arbolejos están en unos pedazos de secano de este alfaquí. Continúan otros diez aceitunos en fincas del Maalenal, otro en la Gena alinda con el camino y tierra de Alboroc. En la falda del monte se detalla otro alindando con las propiedades del Boroc. En el pago del Mauçeta hay dos aceitunos, uno en tierra de Hamza y otro en la falda del monte alindando con una de las fincas de la iglesia mayor de Dúrcal o mezquita de Margena. Otros dos aceitunos se encuentran plantados en el Pago de Beninar en tierra de la rábita

marŷe, o marŷe, amaly. Dice Ibn Al-Ŷayāb: (marŷe,) es una superficie de tierra que tiene 40 codos raššašies de lado. Al contrario de qadah, que era para medir las tierras de secano. Esta medida solía variar entre unas zonas y otras del reino. El marjal utilizado en la Vega de Granada valía 100 estadales cuadrados o 528,24 metros cuadrados. En otros lugares del Reino de Granada y Marruecos utilizaban el marjal de 64 cañas (qașaba), o 436,7106 metros cuadrados. En Lugo y Orense y en Ugíjar, utilizaban el marjal que valía 625 varas castellanas, 5. 625 pies cuadrados, 436,7106 metros cuadrados, mientras que el marjal de Orgiva, Motril, Granada, y Santafé, era de 500 metros cuadrados; en otras zonas, equivalía a 527 metros cuadrados. Dependía de la calidad de la tierra, cuanta más agua tiene el marjal es más pequeño pues la producción es elevada. 
Beninar junto a una acequia. Otro está plantado en tierra de Almoharcaz, lo comparte el afaquí con la rábita de Belena.

\section{HABICES DE LA RÁBITA DE MARGENA}

Este centro religioso contaba con bienes habices propios del edificio que se pueden ver en el cuadro siguiente:

Bienes
Haza
Haza
Haza
Haza
Haza
Hazas
Haza

$\begin{array}{ll}\text { Ubicación } & \text { Superficie } \\ \text { Pago de Margina } & 1 \text { marjal } \\ \text { Pago de Margina } & 2 \text { marjales } \\ \text { Pago de Azuar } & 1 \text { marjal } \\ \text { Pago del Mauçeta } & 1 \text { marjal } \\ \text { Pago de Abdarof } & 2 \text { marjales } \\ \text { Pago del Valat } & 3 \text { marjales } \\ \text { Pago de Margina } & 1 / 2 \text { marjal }\end{array}$

\author{
Linderos \\ Alboroc y camino \\ el Boroc \\ rábita Azuar y habices escuela \\ camino y Abenmuça \\ Foton, acequia y camino \\ Azorzal y acequia \\ Alazeraque y torre
}

Las tierras de los habices de esta rábita o iglesia estaban destinados a la conservación del edificio y a los gastos del culto. En total suman diez marjales y medio de tierra de regadío. En el Pago de Margena o Margina se detallan varias de ellas. La primera de las hazas, de un marjal, tiene como linderos las posesiones de Alboroc y el camino. La segunda, de dos marjales, estaba junto a la anterior y por otra parte las fincas del Boroc. La última, de medio marjal, alinda con las heredades de Alazeraque y con la torre misma. En el Pago de Azuar encontramos un marjal alindando con posesiones de los habices de la escuela y con la rábita denominada Azuar. Otro marjal se detalla en el Pago del Mauçeta junto a un camino y fincas de Abenmuça. En el Pago de Abdarof se delimitan dos marjales que presentan como linderos las heredades de Fotón, la acequia y un camino. Otros dos pedazos de tierra pequeños alcanzan la superficie de tres marjales, en el Pago del Valat, alindan con una acequia y las fincas de Azorzal.

Otros habices detallados en este barrio son los designados a los mezquinos, son tres pedazos de tierra de distinta extensión. El primero de ellos alcanza una extensión de tres marjales, en el Pago de Margena, alindando con las fincas de Abdilhac y Alpuxarri. La segunda, de marjal y medio, alinda con las de Aben Eluyn y las de Alazerac. La otra, de tres marjales, está delimitada por las de Zubey y Alazerac. Según expresión del escribano estos habices de los mezquinos se encuentran en el llamado "Varrio de Margina".

Los habices de los cautivos de este lugar cuentan con cuatro hazas en el Pago de Margena. La primera, de dos marjales, alinda con posesiones de Alazerac y con la sierra. La segunda, de tres marjales de cultivo, está situada junto a las de Alpuxarri y un camino. La tercera, de dos marjales, está delimitada por el camino y las heredades de Abdilhac. La última, de dos marjales, alinda con las de Alpuxarri y las de el Muleh Alí. En total tienen los cautivos una extensión de nueve marjales de regadío en este lugar del Valle de Lecrín. 
Los bienes destinados a la conservación y buen uso de la acequia son denominados por los conocedores como habiz açequia. Son otras cuatro hazas de regadío en el Pago de Margena que suman una extensión de once marjales. La primera de las descritas tiene cuatro marjales y alinda con las de Aben Eluyn y las del Boroc. Otra de un marjal lo hace con las de Alpuxarri y Alazraquir. La tercera, de tres marjales, está delimitada por las de Alharrac y la acequia. La restante, de tres marjales, tiene como linderos las posesiones del conde de Tendilla y el camino.

Además cuando se describen las tierras de la rábita o iglesia de Margena encontramos una haza de dos marjales que alinda con la iglesia y las posesiones del Haberuc, nos dice el apeador de los bienes que pertenecía a los habices de las sepulturas. Otras dos hazas en este mismo Pago de Margena, una de medio marjal y la otra de un marjal, tienen el destino de conservar el pozo, es decir son habices con esta finalidad concreta. La primera de ellas más extensa alinda con la acequia, el camino y fincas de Almontaral y Gebeli. La otra más pequeña alinda con el camino y las heredades de Zobede. Por último, encontramos otra finca, de un marjal, que alinda con las de Abdilhac y el Maleali, pertenece a los habices denominados leylas.

\section{HABICES DE LA RÁBITA DEL BARRIO DE AZUAC O AZUAR}

Este centro religioso en 1502 estaba destinado al culto cristiano pues aparece como una ermita, no sabemos bajo que advocación estaba consagrada en aquellos momentos. En época musulmana esta rábita tenía asignados una serie de bienes habices que pasamos a estudiar a continuación. Posiblemente estuvieran controlados por un alfaquí pues a continuación se nos detallan otros bienes propios del edificio.

$\begin{array}{llll}\text { Bienes } & \text { Ubicación } & \text { Superficie } & \text { Linderos } \\ \text { Hazas } & \text { Pago de Zuac } & 19^{\prime} 5 \text { marjales } & \text { Varios } \\ \text { Hazas } & \text { Pago del Mauçet } & 6 \text { marjales } & \text { Varios } \\ \text { Casa } & ----------- & ----------- & \text { Array y Yezid } \\ \text { Horno } & \text { Hauc Azuac } & ----- & -------\end{array}$

En el primero de los Pagos se describen en total catorce hazas de riego. La primera de ellas alcanza un marjal, alinda con las posesiones de Abdilhac y un barranco. Continúa otra de medio marjal alindando con las del Beni y Al Majar. Otra de dos marjales está situada junto a un macaber u osario de este Pago donde se entierran los creyentes además de tener como lindero una finca de Buçeila. Un marjal y medio de extensión tiene otra que está situada al lado de las del alfaquí Hamet y las de Ben Horaym. Al lado del camino de este Pago se describe otra de medio marjal junto a las de Abulfaçan. También se detalla otra de un marjal junto al camino y las posesiones de Abenmuça. Otros dos marjales de cultivo hay en otra alindando con las de Pahpaz y Almotaruz. En este mismo camino hay otra de un marjal y medio junto a las de Farax Alnono. Tres marjales de cultivo alcanza otra que alinda con las propiedades del alguacil Gia y el camino. Otro marjal alinda con una de las fincas de los habices de la torre o alminar de la iglesia y una acequia del Pago de Zuac. 
Esta rábita es propietaria además de otras tierras en el Pago de Zuac como ocurre con otro marjal y medio que alindan con las fincas de Pahpaz y Alequez Egay. La misma superficie alcanza otra junto a las de Albeni y Moren. Sigue otra con la misma extensión al lado de las del alguacil Gia y de Buçeila. Un marjal se sitúa al lado de la acequia y las tierras de Çaet Array. En el Pago del Mauçet se detallan dos fincas de estos habices. La primera, de cuatro marjales, presenta como linderos las posesiones de Açequi y las de Aben Muça. La segunda, de dos marjales, alinda con las de Azarran y el camino del Pago. Por último se nos describen dos bienes situados en el casco urbano. El primero es una casa que pertenece a la iglesia o rábita que tiene como linderos las viviendas de Array y las de Yezid. El segundo de los bienes es un horno de pan cocer que estaba edificado en el barrio de Hauz Azuac donde estaba situada está rábita propietaria de estos bienes habices.

\section{BIENES DE LA IGLESIA O RÁBITA}

Destinados a la conservación del edificio de la rábita o nueva iglesia cristiana se nos describen varias fincas y algunos árboles. En el caso de las tierras algunas son de riego y otras de secano. Los árboles los estudiamos a continuación de estas posesiones. Las tierras se agrupan de la siguiente manera.

La primera de las fincas de regadío se ubica en el Pago de Zuac, de tres marjales, alindando con las del alguacil Gia y una alberca ubicada en este Pago. Otra de dos marjales alinda con las de Açequi y las de Alcaçar. Otra de tres marjales alinda con las de Alequez Eguy y de Alnono. En cuanto a las tierras de secano encontramos un pedazo, de un cadae de extensión, que alinda con las de Alnadir y una acequia. En el Pago del Meçan hay otro secano de dos cadaes y medio junto a las de Aleduy y el Maqueçan. La última, en el Pago de Levy tiene 5 cadaes de superficie y alinda con las propiedades de Alazeraque y una acequia. Los árboles de está rábita se encuentran plantados en los siguientes lugares de la alquería. Son morales y aceitunos lo que nos indica la importancia de la seda y del aceite en una economía rural como es la de la alquería de Dúrcal en el Valle de Lecrín.

\begin{tabular}{ll} 
Pago & Árboles \\
Pago de Zuac & 3 morales \\
\hline Junto al horno & 1 moral \\
-------------- & 3 morales \\
----------- & 1 moral \\
----------- & 1 aceituno \\
----------- & 1 aceituno \\
------------- & 1 aceituno \\
\hline------------ & 1 aceituno \\
---------- & $1 / 2$ aceituno \\
Pago del Mauçeta & $1 / 2$ aceituno \\
----------- & 1 aceituno \\
& 1 aceituno \\
& 1 aceituno
\end{tabular}

Tierra
tierra habices
tierra alfaquí Hamet
------------
tierra de Abdulaziz
tierra de Yezid
tierra de Ofaymar
tierra de Moren
tierra de Abdala Mudejar
tierra alfaquí Beni
tierra del alguacil Obeyde
tierra de Ubecar Almerini
tierra del Geleli
tierra del Borayuchi

Tierra

tierra habices

tierra alfaquí Hamet

tierra de Abdulaziz

tierra de Yezid tierra de Moren tierra de Abdala Mudejar tierra alfaquí Beni tierra del alguacil Obeyde tierra de Ubecar Almerini tierra del Borayuchi 
Los primeros tres morales están en el Pago de Zuac plantados en una pequeña finca de los habices. Otro moral se encuentra dentro de una de las posesiones del alfaquí Hamet. Otros tres morales están dentro de las casas, es decir en el interior del barrio, junto al horno. El último de ellos está plantado en tierra de Abdulaziz.

Los aceitunos los tenemos distribuidos en varios lugares. El primero de ellos lo encontramos quemado en fincas de Yezid. Otro está en propiedades de Ofaymar. Otro también quemado en tierras de Moren. Otro quemado lo encontramos en las parcelas de Abdala Mudejar. Pertenece a estos habices medio aceituno quemado en tierra del alfaquí Beni, el otro medio pertenecía a la rábita de Belila o Benina. Otro medio lo comparte con la misma rábita y está plantado en finca del alguacil Obeyde, también nos dicen los apeadores que estaba quemado. Otro quemado está en las fincas de Ubecar Almerini. En el Pago del Mauçeta encontramos otro quemado plantado en posesiones del Geleli. El último de ellos, en buen estado de producción se ubica en heredades del Borayuchi. No sabemos nada sobre la producción de estos árboles ni a quien se los arriendan.

\section{HABICES DE LOS CAMINOS DE HAUC AZUAC}

La conservación de caminos es otra de las finalidades de algunos habices donados por los creyentes musulmanes, esto nos indica la importancia de las comunicaciones dentro de los núcleos de población y a la vez la interrelación de unos núcleos de viviendas con otros. Entre los bienes de habices de Dúrcal se describen pertenecientes a los caminos varias hazas. La primera de ellas en el Pago de Azuac, de marjal y medio, que tiene como linderos las posesiones de García de Rojas y el camino del Pago. Otra haza se ubica en el Pago de Almauçeta, de marjal y medio de superficie, alindando con las de Alpuxarri y las de Abul Haçan Almuhah. Otro pedazo de tierra de un marjal se detalla en el Pago de Belina alindando con las de Almontarax Zerrile. Por último, en el Pago de Mergena tenemos otro marjal y medio junto a las tierras de Alboroc y las viñas de este lugar.

\section{HABICES DE ÇUBIA}

Este tipo de bienes estaban destinados según nos dice el escribano "para dar de çenar una noche a los que hagan el nacimiento de Mahoma". Encontramos dos hazas y varios árboles. La primera de las tierras estaba en el Pago de Belina, de dos marjales de superficie, lindera a las eras del lugar y posesiones del alguacil Hernando de Çafra. La otra de la misma extensión y en el mismo Pago alinda con las de Abdulaziz y de Aluba. Los árboles son dos aceitunos, uno quemado plantado en tierras de Alequezevy, el otro en heredades del Marini. Además se nos describe una casa caída levantada en el Pago de Belina alindando con las propiedades del Mondejal y las de Abenhixim. Esta construcción respondería a una casa de campo

\footnotetext{
${ }^{9}$ Así se recoge en la página 29 del manuscrito.
} 
levantada en una de las tierras de uno de los vecinos de la alquería donada posteriormente a estos habices.

\section{HABICES DEL BARRIO DE ALMAUÇETA}

En este barrio conocemos dos rábitas llamadas la Alta y la Baja. El apeador de los bienes nos da una relación detallada de cada uno de ellos y nos va especificando a que centro religioso pertenecen. Los bienes quedan distribuidos de la siguiente manera.

\section{HABICES DE LA RÁBITA DE ALMAUÇETA}

En el barrio de Mauçeta o Almauçeta encontramos varios centros religiosos con sus respectivos habices. La rábita principal o iglesia de este lugar es dueña de varias tierras, árboles y bienes urbanos. Entre los habices asignados al alfaquí y otros gastos encontramos los siguientes.

$\begin{array}{llll}\text { Bienes } & \text { Ubicación } & \text { Superficie } & \text { Linderos } \\ \text { Haza } & \text { Pago Marjina } & \text { 1'5 marjales } & \text { Boroc y las viñas } \\ \text { Haza } & ----------- & 1 \text { marjal } & \text { Abdilhac y Alguaxari } \\ \text { Haza } & --------- & 3 \text { marjales } & \text { Gebeli y Abdilhac } \\ \text { Hazas } & \text { Pago del Mauçeta } & 4 \text { marjales } & \text { Varios } \\ \text { Tierra } & -------------- & 1 \text { marjal } & \text { Abdalaziz, Aben Muça y acequia } \\ \text { Haza } & ---------- & 2 \text { marjales } & \text { Abdalaziz y acequia } \\ \text { Haza } & ------------ & 1 \text { marjales } & \text { Alaxara, habices y camino } \\ \text { Tierra } & ----------- & 1 \text { marjal } & \text { Muça y Tobarri } \\ \text { Tierra } & ------ \text { marjal } & \text { Muça y Azerreb } \\ \text { Casa } & \text { el Mauçeta } & --------- & \text { Abulhaçan Almuhaf y Mahomad } \\ \text { Huerta } & --------- & ------- & \text { Abdulaziz y el Guaca } \\ 1 / 2 \text { horno }^{10} & \text { el Mauçeta } & ----- & ---------\end{array}$

Las hazas son de regadío al decirnos los apeadores las extensiones que alcanzan. En el Pago de Marjina o Margena se detalla la primera de ellas con sus linderos correspondientes. Otras dos de ellas no sabemos el nombre del Pago donde están ubicadas, una tiene un marjal y la otra tres. En el Pago del Mauçeta se detallan dos fincas, una de tres marjales y la otra de uno, cada una de ellas con sus linderos. Otras dos junto a la acequia alcanzan superficies de uno y dos marjales. Sigue otra de un marjal y medio alindando con las posesiones de Alaxara y una finca de habices pertenecientes a la rábita Alolia y un camino. Las otras dos heredades tienen un marjal y la más pequeña es de medio marjal.

Entre los bienes urbanos encontramos una casa en el barrio que tiene como linderos Abulhaçan Almuhaf y Mahomad. La huerta tiene una higuera, no sabemos el lugar donde esta situada ni la extensión que alcanza, alinda con propiedades de Abdulaziz y el Guaca. En el caso del horno estaba compartido con la rábita

\footnotetext{
${ }^{10}$ La otra mitad del horno es de los habices de la rábita llamada Almauçeta Alolia.
} 
conocida como Almauçeta Alolia. Tampoco sabemos nada sobre la extensión ni linderos de este inmueble. La rábita tiene asignados una relación de bienes para la conservación del edificio y gastos del culto, esteras, lámpara, aceite, etc. Nos dicen los apeadores que se detallan los bienes que describimos a continuación. En el Pago del Mauçeta encontramos tres hazas de riego, la primera de ellas de un marjal alinda con las de Azerrer, un osario o macaber donde se entierran los creyentes y heredades de Muça. La segunda, de tres marjales, alinda con Azerre y una de las posesiones de los habices de los pobres. La tercera, de dos marjales, alinda con las de Abdulaziz y Muça. Otras dos fincas alcanzan una extensión de un marjal cada una, la primera está junto a las fincas de Çumayman y Alnadir, la otra alinda con las de Algebeli y el macaber del Pago del Mauçeta.

En el Pago de Abdorrof se describe una haza, de dos marjales, alindando con una acequia y fincas de Alborayach. Un marjal y medio de tierra tiene como linderos las propiedades de Himiz y el acequia. Otro marjal con cuatro morales tiene como colindantes las tierras de Abral Buçula y de Farax Alnono.

En cuanto a los árboles se detallan cuatro morales en una haza de un marjal, dos de ellos pertenecen a los habices de la rábita Alta y los otros dos de la rábita Baja. Los aceitunos están plantados en distintas tierras. Así ocurre con un aceituno en el Pago de Zucar en el osario o macaber de este Pago. Otro en el Pago del Mauçeta está en heredades del Muhali. Otro en tierra del Malen Ali. Otro en el Pago de Mergina en tierra de Aluyn. Otro en el Pago del Mauçeta en tierras de Mahamed Maçot. En el osario o macaber del Pago de Abdarrof hay otro aceituno de estos habices. Otro en tierras de Lazerac. El último de ellos en el Pago de Abdarrof está plantado en posesiones de Muça.

\section{HABICES DE LA RÁBITA ALMAUÇETA ALOLIA}

Esta rábita fue convertida en ermita por los cristianos aunque no sabemos bajo que advocación estaba destinada. Tenía una serie de habices que pasaron a la iglesia del lugar de Dúrcal, antes en época musulmana pertenecían estos bienes a la rábita llamada Almauçeta Alolia. Los bienes de este centro religioso son los siguientes.

$\begin{array}{llll}\text { Bienes } & \text { Ubicación } & \text { Superficie } & \text { Linderos } \\ \text { Haza } & \text { Pago de Mergina } & 1 \text { marjal } & \text { Alpuxarri y camino } \\ \text { Tierra } & ---------- & 1 \text { marjal } & \text { Alboroc y Alpuxarri } \\ \text { Hazas } & \text { Pago del Mauçeta } & 12 \text { marjales } & \text { Varios } \\ \text { Horno } & ------------ & ------- & \text { Atobarri y la rábita } \\ \text { Casa } & ------- & ---\end{array}$

La primera de las tierras se ubica en el Pago de Mergina al lado de las de Alpuxarri y un camino, otra de ellas de un marjal tiene como linderos las de Alboroc y Alpuxarri. En el Pago del Mauçeta se contabilizan seis fincas, la primera de ellas es de marjal y medio de extensión, alindando con las de Atobarri y el Comir. 
La segunda, de la misma superficie, tiene como linderos el edificio de la rábita de Almauçeta y la vivienda de uno de los vecinos del lugar llamado Xeyl. La tercera, de tres marjales, alinda con las propiedades de Abdulaziz y de Almahaja. Otro marjal y medio alcanza la cuarta que alinda con las de Atobarri y las de Muça. Otros tres bancales suman otro marjal y medio de cultivo que alinda con las heredades de Halid y de Abolafis. La última, de tres marjales, está situada junto a las del Nadir y un camino.

Entre los bienes urbanos de esta rábita se nos describe un horno. La mitad de este inmueble es de la rábita de Almauçeta y la otra mitad de esta rábita denominada Almauçeta Alolia, es decir en el barrio de Almauçeta hay dos centros religiosos denominados el Alto y el Bajo. No tenemos más datos sobre esta construcción tan importante para obtener ingresos para la rábita y el personal que la sirve. A continuación se detalla la existencia de una casa que pertenece a la rábita, esta alindado con los bienes de Atobarri y el edificio de la rábita, posiblemente fuera la vivienda del alfaquí que servía al centro religioso. Tampoco sabemos nada más sobre esta construcción.

Además pertenecen a este centro religioso una serie de aceitunos. El primero de ellos está en el Pago de Almauçeta plantado en tierras de la acequia. Otro cerca de este alinda con la huerta de Hamza. Un tercio de otro pertenece a esta rábita y los otros dos tercios son del edificio de la rábita ${ }^{11}$. Otro medio es de la rábita y el otro medio es de Muça, está plantado en una de las fincas de Tobarri. Otro quemado está en posesiones de Muça. Otro se describe en tierras de Tobarri. Otro cuarto de otro lo comparte con el Puxarri ${ }^{12}$. Tres de ellos están plantados en posesiones del Puxarri. Otro en el Pago de Zucar estaba en fincas del Mahuja. Otro en el Pago de Almauçeta estaba en tierras de Rica. Otro quemado se encontraba en heredades de Zereb. Otros dos tercios de otro lo comparta con la rábita de Almauçeta Baja ${ }^{13}$. Otra mitad de otro lo comparte con Çaumayam. Otro estaba plantado en una de las fincas de los habices de los cautivos es esta alquería. En el Pago de Abdorrof estaba en tierras de la acequia. El último de ellos en el Pago de Margina en tierras de Aluzeraque.

Entre los bienes destinados al edificio de la rábita o propios de la iglesia como expresa el escribano encontramos una haza en el Pago de Almauçeta, de tres marjales, que alindan con las tierras del Maalen Ali y con el edificio de la rábita Baja.

\section{HABICES DEL ALFAQUÍ DE LA RÁBITA DEL BARRIO DE ABDARROF}

Este centro religioso fue convertido en ermita por los cristianos. Muchos de sus bienes eran controlados por el alfaquí que lo servía. Los bienes son los siguientes.

\footnotetext{
${ }^{11}$ Los dos tercios son para la conservación del edificio de la rábita ya convertida en iglesia por los cristianos.

${ }^{12} \mathrm{El}$ escribano al margen del documento dice que es medio aceituno de la rábita, aunque en el texto dice que es una cuarta parte.

${ }^{13} \mathrm{El}$ escribano dice al margen que es la mitad de este árbol aunque en el texto se alude a dos tercios. El tercio restante es de la rábita Baja de Almauçeta.
} 


\begin{tabular}{|c|c|c|c|}
\hline Bienes & Ubicación & Superficie & Linderos \\
\hline Hazas & Pago de Abdarrof & $11^{\prime} 5$ marjales & Varios \\
\hline Haza & ---------------- & 3 marjales & Alcoton y alfaquó Hamet \\
\hline Haza & ---------------- & 2 marjales & Albidix y Alcoton \\
\hline Haza & ---------------- & $1 / 2$ marjal & Açomaya y habices \\
\hline Haza & -------------- & 2 marjales & Axoayuf y Aldilari \\
\hline Hazas & Pago del Mauçeta & 5'5 marjales & Varios \\
\hline Casa & Barrio de Abdarrof & [---------- & Hamge y el horno \\
\hline Horno & Barrio de Abdarrof & E ------------ & ----------------- \\
\hline Haza & --------------- & 1'5 marjales & Arraçaçar y Almarchi \\
\hline Haza & --------------- & 5 marjales & Halid y Buçula \\
\hline Haza & -------------- & 3 marjales & Varios \\
\hline Haza & --------------- & 4 marjales & camino y acequia \\
\hline Haza & --------------- & 1 marjal & Açomaya y habices \\
\hline Haza & ----------------- & 4 marjales & habices y acequia \\
\hline Haza & ---------------- & 2 marjales & acequia y Açomayam \\
\hline Haza & --------------- & 2'5 marjales & Varios \\
\hline Haza & ----------------- & 5 marjales & Almahajael \\
\hline Haza & --------------- & 1'5 marjales & horno y calle \\
\hline Hazas & Pago de Beninar & 13 marjales & Varios \\
\hline Haza & --------------- & 2 marjales & Almoçaguaz y Alfacar \\
\hline Hazas & Pago de Almauçeta & 5'5 marjales & Varios \\
\hline Haza & ------------ & 1'5 marjales & Alpuxarri y habices \\
\hline Haza & --------------- & 1 marjal & Acçan Açagar y acequia \\
\hline Haza & --------------- & 2 marjales & Atobarri y acequia \\
\hline Hazas & Pago de Zucac & 3,5 marjales & Varios \\
\hline Haza & ---------------- & 3 marjales & Varios \\
\hline Haza & --------------- & 1 marjal & Pahpaz y acequia \\
\hline Haza & --------------- & 1 marjal & Azerrib y camino \\
\hline Haza & --------------- & 1 marjal & Albeni y Pahpaz \\
\hline Haza & ---------------- & 1 marjal & García de Rojas y Abuloli \\
\hline Haza & --------------- & 3 marjales & acequia y Moron \\
\hline Haza & -------------- & 3 marjales & camino y Nono \\
\hline Haza & --------------- & 2'5 marjales & Ohaymed y acequia \\
\hline Haza & --------------- & 4 marjales & Alhaçar y acequia \\
\hline Haza & Pago de Belina & 2 marjales & Axoa Yahi y Abuzeraque \\
\hline Haza & Pago de Marchina & 4 marjales & Axoayah y Abdilhac \\
\hline Haza & Pago de Margena & 3 marjales & Alpuxarri y Alazeraque \\
\hline Secano & Pago de Zucar & 1 cadae & las eras y acequia \\
\hline Secano & ---------------- & 3 cadaes & castillo y barranco \\
\hline Casa & ---------------- & ----------- & iglesia mayor \\
\hline Horno & Leuxa & ---------- & ----------------- \\
\hline Huertas & ---------------- & ---------- & Alborça y casa \\
\hline Haza & Pago de Zucar & 1 marjal & Farax, Alnono y Boçila \\
\hline Viña & Pago de Xenatar & 1'5 marjales & Alnono y acequia \\
\hline
\end{tabular}

Entre los bienes asignados al alfaquí de esta rábita encontramos hazas de riego, viñas, secanos y árboles frutales y no frutales. En cuanto a las tierras de riego encontramos en primer lugar en el Pago de Abdarrof una haza, de dos marjales, que alinda con las tierras de Abenaron y una acequia. Otra junto a un camino y las 
posesiones de Aljurreçayf tiene un marjal de superficie. Otra de las hazas es de cuatro marjales de extensión que alinda con una acequia y fincas de Alabar. A continuación se detallan tres pedazos de tierra juntos en este Pago que suman tres marjales de superficie, presentan como linderos el camino y las heredades de Alfacar. La última de ellas pertenece la mitad a los bienes del alfaquí y la otra mitad a los habices de los pobres, los linderos que presenta son las tierras de Alborayach y las casas del barrio ${ }^{14}$.

Tenía otra haza, de tres marjales, alindando con las de Alcoton y del alfaquí Hamet. Otra de dos marjales alinda con las de Albidix y Alcoton. La siguiente, de medio marjal, tiene como colindantes las de Açomaya y una fincas de los habices de la Algima Alquibir o Iglesia mayor de la alquería. Otros dos marjales alcanza otra situada junto a las de Axoayuf y las de Aldilari. En el Pago del Mauçeta se describen varias fincas. Una de ellas, de un marjal y medio, alinda con las de Alpuxarri y el camino. Otra de un marjal alinda con las de Alfoluz y el alfaquí Hamet. Otra de dos marjales lo hace con las de Azerrer y Albidix. Otro marjal alinda con una de las fincas de los habices de los pobres y la acequia.

Entre los bienes urbanos se detalla una casa ubicada en el Barrio de Abdarrof que tiene como linderos por una parte la vivienda de Hamge y por otro el horno de la rábita. Esta sería posiblemente la morada del alfaquí que servía a este centro religioso. También se alude a un horno de los habices que era utilizado por los vecinos de este lugar pues nos dice el escribano que era el horno de la alquería. Los hornos cumplen un papel económico importante al proporcionar abundantes rentas para el culto en los centros religiosos musulmanes. Muchos de ellos pertenecieron a los habices por donación de los creyentes y otras veces porque las mezquitas los construían para sacar beneficios.

El escribano tras aludir a los bienes propios del edificio de la rábita ofrece otra relación de bienes asignados al alfaquí. Entre ellos se describe una haza, de marjal y medio de cultivo, que alinda con las propiedades de Arraçaçar y de Almarchi. Otros dos pedazos suman cinco marjales, con un moral, que tienen como linderos las tierras de Halid y de Boçula. Otra de tres marjales alinda con las de Adilari, Almohayxa e Himiz. Continúan otros dos pedazos de tierra juntos, de cuatro marjales de extensión, que tienen como linderos un camino y una acequia. Otro marjal de tierra alinda con Açomaya y una de las fincas de los habices de la rábita Abdarrof. Otra haza alcanza cuatro marjales de cultivo, alinda por una parte con tierras de habices de la rábita Belinar y por otro con una acequia. Otra, de dos marjales, está situada al lado de la acequia y posesiones de Açomayam. Otra tiene dos marjales y medio de superficie, alinda con las heredades de Abolafya y las de García de Rojas. Otra de cinco marjales era denominada por los vecinos del lugar como Fadin Almohzen, alinda con las tierras de Almahajael. Otra de las fincas con nombre propio era denominada Fadin Alfor, nos dice el escribano "ques en las casas del logar"15, alinda con el horno y la calle, tiene un marjal y medio de extensión.

\footnotetext{
${ }^{14}$ Es muy común encontrarnos fincas e inmuebles compartidos entre varios tipos de habices.

${ }^{15}$ Libro de Habices de 1502, pág. 36.
} 
En el Pago de Beninar encontramos tres hazas. La primera de ellas, de siete marjales, alinda con las de Almoçaguez y la acequia. La segunda, de tres marjales, está colindante a las de Yezid y el Foluz. La tercera, de tres marjales, tiene como linderos las propiedades del alfaquí Ben Atyb y las de Azerref. Continúa otra de dos marjales junto a las de Almoçaguaz y Alfacar. En el Pago de Almauçeta se ubican cuatro hazas de estos bienes. La primera de ellas, de dos marjales, alinda con las de Atobarri y el camino. La segunda, de un marjal, alinda con las de Alpuxarri y el alfaquí Benaçam. La tercera, de un marjal, lo hace con las de Alpuxarri y Aben Atym. La cuarta, de marjal y medio, alinda con las heredades de Alhaçar y las de Yça. Otra haza de marjal y medio tiene como propiedades colindantes las de Alpuxarri y una de las fincas de los habices de los pobres. A continuación se describe otro marjal junto a las propiedades de Acçan Açagar y la acequia. Otros dos marjales se ubican al lado de las de Atobarri y la acequia.

En el Pago de Zucac se describen otras tres fincas. Una de ellas de un marjal alinda con las de Alnefçaelmon. Otra de otro marjal alinda con las de Achaubi y una acequia. Un marjal y medio tiene otra que está junto a las de García de Rojas y el Nono. Otra de tres marjales alinda con las fincas de Alnuçaquiz y las de Mohomed Moçala. Otra de un marjal está al lado de las de Pahpaz y la acequia. La misma extensión presenta otra que alinda con las de Azerrib y el camino. Otra lo hace con las de Albeni y Pahpaz. La otra con la misma superficie lo hace con las de García de Rojas y Abuloli. Tres marjales de superficie alcanza otra alindando con las de Moron y una acequia. De la misma extensión es otra junto a las del Nono y un camino. Dos marjales y medio alcanza otra situada junto a las de Ohaymed y la acequia. Otra tiene cuatro marjales alindando con las de Alhaçar y la acequia.

En el Pago de Belina encontramos otra haza, de dos marjales, que alinda con las de Axoa Yahi y la de Abuzeraque. En el Pago de Marchina se describe otra de cuatro marjales que alinda con las de Axoayah y las de Abdilhac. Otra haza, de tres marjales, la encontramos en el Pago de Margena, alinda con las tierras de Alpuxarri y Alazeraque. En el Pago de Zucar hay un marjal, con tres morales, junto a las posesiones de Farax, Alnono y Boçila. En este mismo Pago tenemos un secano, de un cadae ${ }^{16}$ de sembradura, situado junto a las eras y una acequia. Otra finca de secano se sitúa al lado del castillo, de tres cadaes de superficie, alindando con la

${ }^{16}$ El cadae es una medida utilizada preferentemente en las tierras de secano. QADAH o CANTARA,es una medida de capacidad y de superficie. Era una vasija en forma de tronco de pirámide, cuyos lados tenían la forma de trapecios. Según el Tratado de Ibn Abdūn, el qada sevillano, equivalía a una arroba y dos arrates, nos dice: "conviene que en la medida de trigo, y sólo en ella, se haga una barra de hierro que atraviese por medio de la boca del qadah, de una parte a otra, y que en el centro el contraste de que contiene justo el equivalente al peso de una arroba, una vez lleno el qadah, ha de rasarse la medida con un listón de madera, lo bastante grueso para que no se curve, o con una varilla de hierro, que se pasará por encima de los bordes del qada y, de la barra de hierro que los atraviesa, con lo cual quedará patente cualquier exceso en la medida. Sería de desear que el qadah tuviese una arroba y dos arrates", o 27 libras, mientras que en Córdoba equivalía a 30 libras. Al mismo tiempo el qadah de trigo y mijo oscilaba entre 30 y 34 libras, dependiendo de la zona. El alqadah utilizado en España equivalía a 14 litros, mientras que el alqadah granadino equivalía a media fanega castellana o dos celemines moriscos. 
fortaleza y un barranco. Este dato nos permite conocer la fortaleza de este lugar. La última de las fincas es una viña en el pago del Xenatar, de marjal y medio, alindando con las tierras de Alnono y una acequia.

Entre los bienes urbanos asignados al alfaquí se nos detalla la existencia de una casa de la rábita o iglesia que alinda con el edificio religioso musulmán convertido en iglesia por los cristianos. Tiene además dos huertas pequeñas al lado de la vivienda con unas parras y cinco morales pequeños calificados de moralejos, no sabemos la extensión de estas tierras, los linderos que presentan son por un lado las posesiones de Alborça y por otro la casa de los habices. También controla el alfaquí el horno denominado de Leuxa, es decir del lugar de Leuxa.

Entre los árboles que controla el alfaquí se describen varios morales y aceitunos. El primero de los morales se encuentra dentro de una haza de los habices. Otros tres morales tenemos en una haza del Pago de Zucar y unos moralejos en dos huertas ya descritas. A ellos se añade otro moral en el Pago del Mauçeta plantado en una de las fincas del Zarreb. Además encontramos unas parras en las dos huertas pequeñas. En cuanto a los aceitunos encontramos uno plantado en una de las hazas de los habices junto a una acequia. En el Pago de Abdarrof hay un aceituno que se encuentra en tierra del acequia alindando con Alnefça. Otro aparece en tierra de Façan Amiguer. Otro plantado en el osario o macaber. Otro en tierra de Mahomed Alcalay. Otro en tierras de habices de la rábita Belina. Otro en tierra de Tobarri. En el Pago del Mauçeta se encuentra otro plantado en fincas de Ali el Cordoni. Pertenecen al alfaquí dos tercios de otro aceituno pues el tercio restante es de los habices de la rábita de Almauceta Alolia. Otros tres aceitunos se encuentran en la falda del monte plantados junto a una acequia. Otro está en tierras de Atobarri. En el Pago de Belina hay un aceituno en fincas del Merini. El último de ellos está plantado en propiedades del Foluz.

\section{HABICES DE LA RÁBITA DE ABDARROF}

Son calificados por el escribano como bienes propios de la rábita. Se destinan a la conservación del edificio religioso y gastos del culto. En total encontramos nueve fincas y varios aceitunos. En el Pago de Abdarrof tenemos varias de ellas. La primera, de dos marjales, alindando con las de Maalen Omar, una acequia y las de Tobarri. La segunda, de un marjal y medio, tiene como linderos una de las fincas de los habices de la rábita de Margena y las posesiones de Aben Muça. Otra en este Pago tiene un marjal alindando con el osario o macaber y las de Aluhdar. Continúan dos pedazos pequeños de tierra, de dos marjales, junto a las de Alborayaf y las de Çayde Achine. Otros dos marjales tiene otra junto a las de Alborayache y las de Abolafia. Otros dos marjales alindan con Açomaya y un camino. En el Pago de Zucar hay dos hazas. La primera, de dos marjales, alinda con Alfacar y Nono. La otra, de un marjal, alinda con habices de la rábita Azuac y las de Alonso de Baeça. En el Pago de Belin hay dos marjales junto a las de Almaalen Mahomad y habices de los cautivos.

Los aceitunos se ubican en varios lugares. El primero en el Pago de Abdarrof en tierras del Puxarri. Otro en fincas del Nefça. Otro en posesiones de Hamet Benfilel. En el Pago de Belina tenemos otro en tierras de los habices de la rábita de Belinar. 
Otro pie de aceituno quemado estaba en heredades del Moçaguaz Alnono. En el Pago de Zucac hay dos aceitunos plantados en las posesiones de Alonso de Baeça. Estos son los bienes cuyas rentas se destinan al edificio y gastos del culto.

\section{HABICES DE LOS POBRES.}

Algunos bienes de habices se destinan a sufragar gastos de los pobres o necesidades de esta población, no son lo mismo que los mezquinos pues se detallan cada uno de ellos por los conocedores de los habices. Los pobres de Dúrcal tenían como bienes habices una serie de tierras y árboles. Entre las tierras destacan las situadas en el Pago de Abdarrof, Belena, Zucar, Mauçeta o Almauçeta y otros lugares de la población. Las hazas del Pago de Abdarrof tienen una de ellas un marjal y medio y la otra un marjal. La primera alinda con las propiedades de Alborayach y las casas del barrio. La segunda está junto a las tierras de Juriçay y una acequia. Otra haza de los pobres alcanza dos marjales y medio, alinda con las de Alfacar y las de Hamet Azerrer. Otros dos marjales tiene otra junto a la acequia y fincas de Alabare. Otra de un marjal y medio lo hace con las de Ali Ozbeydala y el edificio de la rábita Abdarrof. Otra haza es calificada como fadin o campo, de un marjal y medio de superficie, tiene como linderos las posesiones de Yça y la acequia. Otra de tres marjales alinda con las de Açan Açaguer y Çogayam. Tenemos otra de un marjal y medio junto a las de Abdala Almudejar y Azarrib.

En el pago de Belena tenemos dos hazas. La primera de ellas, de dos marjales, alinda con Xoayuh y Ohaymet. La segunda, de marjal y medio, tiene como colindantes las de Alnono y el Eduy. Otra de tres marjales está al lado de las de Abdala Almudejar y Zibrini. La siguiente tiene marjal y medio alindando con las de Alcoton y una acequia. En el pago de Zucar se describen otras dos fincas, una de cuatro marjales, junto a las de Azarrab y Chaubi, la otra de un marjal alinda con Alnono y Moren. En el Pago del Mauçeta hay tres marjales que alindan con las de Buçaila y Guaçar. A continuación se detalla otra de dos marjales que está delimitada por las de Abdilhac y las de Tybira Tobarri. En el Pago de Almauçeta tenemos otras dos hazas, una de un marjal alinda con Buçaila y Alpuxarri, la otra, de un marjal y medio, alinda con las de Hamza y Alguaxari. Otro marjal y medio de tierra alinda con las de Almotarax y la acequia. La última, de un marjal y medio, está delimitada por las de Muça y un camino.

Entre los árboles se detalla un moral en el Pago de Beninar plantado en tierra de Caçan Açaguer. En este mismo Pago tenemos un aceituno en tierras de Obaydala. Otro aceituno se describe en el Pago de Zucaq en tierra de Alonso de Baeça.

\section{HABICES DEL BARRIO DE BELINA O BELINAR}

Es otro de los barrios de esta alquería del Valle de Lecrín, en él se detallan otras dos rábitas llamadas la Alta y la Baja. Los bienes de cada una quedan de la siguiente manera. 


\section{HABICES DE LA RÁBITA BELINA}

Esta rábita fue convertida en ermita por los cristianos como ocurrió con otros muchos centros religiosos del Valle de Lecrín, no sabemos bajo que advocación fue consagrada. Los habices de esta rábita son casi todos terrenos. La primera de las hazas la encontramos en el Pago de Belinar, de un marjal y medio, alindando con las de Hamet Himiz y Adyderi. La otra, de dos marjales y medio, estaba dividida en dos pedazos, alindando con un osario o macaber y el edificio de la iglesia mayor del barrio o mezquita. De la misma extensión es otra que está delimitada por las de Açet Yezid y la mujer de Axir Xoayar. La otra alinda con las posesiones de Mafamed, las del alfaquí Ali y Abulafia. Otra de ellas tiene como linderos las de Aben Alhage y las de Hamet Aben Quirima. Dos marjales y medio tiene otra junto a las de Adyde y Alafdar. En el Pago de Abdarrof encontramos otra, de un marjal, junto a las de Abenjudi y tierras de la rábita de Almauçeta. Otro marjal está situado en el Pago de Mauçeta alindando por todas partes con las fincas de Albeni.

En el caso de los aceitunos tenemos uno en el Pago de Mauçeta plantado en tierras del Guaxari. Otro está en el Pago de Abdarrofen tierras del alfaquí Hamet. Otro del Pago del Mauçeta se ubica en posesiones de Ali Zerrer. Otro medio aceituno es de este centro religioso pues la otra mitad es de los habices de la rábita Almauçeta, está plantado en propiedades del Dyduli. El último de ellos está quemado en tierras de Hamet Hamiz. Entre los bienes urbanos de esta rábita se describe una casa que pertenece a los bienes de la rábita, los linderos que presenta son la morada de Abdala Alfoluz y una acequia. Esta casa se ubica en el barrio de Belina. No tenemos datos sobre la superficie ni distribución del inmueble.

\section{HABICES DE LOS CAUTIVOS}

Entre los bienes encontramos algunos destinados a la redención de cautivos pues podía ocurrir que algunos vecinos de esta zona fueran a la guerra contra los enemigos del Islam y tener la mala fortuna de caer prisionero. Tenemos bienes en estas alquerías que se donaron al castillo de Castell de Ferro en la costa. Los que encontramos en Durcal son descritos así.

Las tierras del Pago de Zucac suman siete marjales y medio, en total son cinco hazas de un marjal y medio cada una. La primera alinda con Abdala Nono y Zerrib. La segunda lo hace con Yezid y Zerrib. La tercera con Çaet Arrayz y el camino. La cuarta lo hace con Abdulaziz y Zerreb. La quinta alinda con las de Moren y Alequezegay. También un marjal y medio alcanza otra que está delimitada por el osario o macaber y un camino. Otra, de tres marjales, alinda con las posesiones del Buy y una acequia. Un marjal y medio tiene otra que está al lado de las de Açomayar y Alborayach.

En el Pago de Belinar hay tres hazas, una de seis marjales, tiene como linderos las del alguacil Apoayaf y el camino, otra de cuatro marjales, alinda con las de Almachi y el Merini, la última, de seis marjales, está delimitada por las de Azerrib y una acequia. En el Pago de Zunir se describe otra de dos marjales que tiene como 
colindantes una de los habices de Belinar y la acequia. En el Pago de Abdarrof tenemos varias hazas de distinta extensión que suman en total catorce marjales. La primera de ellas se denomina Fadin Alcoronbe, de dos marjales, alinda con Açomayam y Ali Obeydala. Otra de dos marjales alinda con Albadix y Azerrib. Otra está partida en dos pedazos que suman cinco marjales de extensión, alindan con Alborayah, Jorrotyf y Albireq. Un marjal alcanza otra situada junto a las de Fadide y Albeni. La última de este Pago tiene cuatro marjales alindando con las de Albedix e Ydumar.

En el Pago del Mauçeta se nos detalla una haza, de un marjal y medio, que presenta como linderos las tierras del alfaquí Ben Atic y las de Abdala Dir. Otra situada en el Pago de Margina es denominada entre los vecinos Fadin Almuhdara, tiene tres marjales de superficie, alindando con las Abdilhac y las de Aben Foray. El último de los bienes es un moral plantado en tierras de Behilel en el Pago de Margina, en el lugar llamado el Mofaja.

\section{HABICES DE LA RÁBITA DE BELINAR LA BAJA}

Esta rábita también fue convertida en ermita por los cristianos aunque desconocemos bajo que advocación fue consagrada.

$\begin{array}{llll}\text { Bienes } & \text { Ubicación } & \text { Superficie } & \text { Linderos } \\ \text { Hazas } & \text { Pago de Zucac } & 4 \text { '5 marjales } & \text { Varios } \\ \text { Haza } & ------------ & 2 \text { marjales } & \text { Hemiz y acequia } \\ \text { Hazas } & \text { Pago de Belinar } & 3 \text { marjales } & \text { Varios } \\ \text { Hazas } & \text { Pago de Abdarrof } & 4 \text { marjales } & \text { Varios } \\ \text { Hazas } & \text { Pago Demauçeta } & 2 \text { marjales } & \text { Varios }\end{array}$

Entre los bienes habices que le pertenecen destacan dos hazas en el Pago de Zucac. La primera de ellas, de tres marjales de cultivo, presenta como linderos las de Abdulaziz y Albeni. La segunda, de marjal y medio, alinda con las tierras de Abdulaziz y un camino. Otra haza de estos bienes alcanza la extensión de dos marjales que están delimitados por las fincas de Hemiz y una acequia. En el Pago de Belinar encontramos tres marjales en dos hazas, la primera de un marjal presenta como colindantes las de Azebrir y las de Almaalen Abdorrof. La otra, de dos marjales, alinda con las de Alfoluz y una haza denominada por los vecinos del lugar como Fadin Alcabar. En el Pago de Abdarrof hay otras dos hazas, una de tres marjales, con linderos que pertenecen a Alcaçar y Alahdar, y la otra, de un marjal y medio, alindando con las de Caçan Aben Alhage y las de Alpuxarri. En el Pago Demauçeta se describen otras dos fincas. Una de ellas, de un marjal, tiene por linderos las de Alnefçe e Yça, la otra, de la misma extensión alinda con las de Al Alen Ali y Abdilfac el Menor.

Respecto a las árboles encontramos un aceituno quemado que estaba plantado en una de las hazas de la rábita Abdarrof. Los morales los encontramos uno en el 
Pago de Zucac en tierras del Nadir. Otro en el Pago de Belinar en propiedades del Zerrib y el último de ellos estaba dentro de una de las heredades del Coton.

\section{CONCLUSIÓN}

Estas son las principales noticias contenidas en el Libro de Habices de 1502 tras la conversión de los mudéjares, fecha muy cercana a la etapa netamente musulmana, no hemos estudiado nada sobre la onomástica ni la toponimia pues en un futuro realizaremos algunos trabajos sobre estos aspectos. Los habices cumplieron funciones muy variadas en la sociedad musulmana, muchos de ellos estuvieron destinados a los centros de culto y a las personas que los servían, pero en otras ocasiones se destinaron a obras caritativas, estudio, comida de caminantes y otras necesidades de los creyentes. Los bienes se arriendan y las ganancias obtenidas pertenecen a los centros religiosos. El conocimiento paulatino de estos bienes permite profundizar en la sociedad musulmana granadina pues nos han llegado gran cantidad de documentos sobre este tipo de bienes gracias a la relación de propiedades que pasaron a las iglesias tras la conquista del territorio. En conclusión podemos decir que la localidad de Dúrcal se conoce más detalladamente desde esta perspectiva pues como hemos dicho hasta el momento no teníamos apenas noticias sobre esta población del Valle de Lecrín. Otras noticias sobre los habices de la iglesia de esta localidad han sido puestas de manifiesto en otro trabajo que constituye la Tesis Doctoral de Lorenzo Padilla Mellado que analiza la comarca del Valle de Lecrín ${ }^{17}$

${ }^{17}$ Lorenzo PADILLA MELLADO: Los habices de las iglesias del Valle de Lecrin: Historia y Arqueología. Granada, 2010. Tesis Doctoral dirigida por M. Espinar Moreno. 